\title{
Nuclear Eg5 (kinesin spindle protein) expression predicts docetaxel response and prostate cancer aggressiveness
}

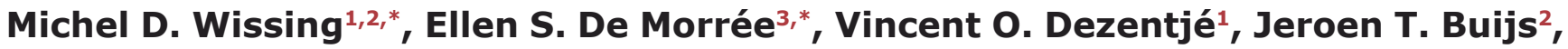 \\ Ronald R. De Krijger ${ }^{4}$, Vincent T.H.B.M. Smit ${ }^{5}$, Wytske M. Van Weerden ${ }^{3}$, Hans \\ Gelderblom ${ }^{1}$, Gabri van der Pluijm² \\ ${ }^{1}$ Department of Clinical Oncology, Leiden University Medical Center, Albinusdreef 2, 2333 ZA Leiden, the Netherlands; \\ 2 Department of Urology, Leiden University Medical Center, Albinusdreef 2, 2333 ZA Leiden, the Netherlands; \\ ${ }^{3}$ Department of Urology, Erasmus MC-Cancer Institute, 's-Gravendijkwal 230, 3015 CE Rotterdam, the Netherlands; \\ ${ }^{4}$ Department of Pathology, Reinier de Graaf Gasthuis, Reinier de Graafweg 3, 2625 AD Delft, the Netherlands; 5 Department \\ of Pathology, Leiden University Medical Center, Albinusdreef 2, 2333 ZA Leiden, the Netherlands. \\ * These authors contributed equally to this work \\ Correspondence to: Michel Wissing, email: m.d.wissing@/umc.nl \\ Keywords: biomarker; docetaxel; Eg5; kinesin spindle protein; prostate cancer. \\ Received: May 01, $2014 \quad$ Accepted: May 16, $2014 \quad$ Published: May 16, 2014
}

This is an open-access article distributed under the terms of the Creative Commons Attribution License, which permits unrestricted use, distribution, and reproduction in any medium, provided the original author and source are credited.

\section{ABSTRACT}

Novel biomarkers predicting prostate cancer ( $\mathrm{PCa}$ ) aggressiveness and docetaxel therapy response of PCa patients are needed. In this study the correlation between nuclear Eg5-expression, PCa docetaxel response and PCa aggressiveness was assessed. Immunohistochemical staining for nuclear Eg5 was performed on 117 archival specimens from 110 PCa patients treated with docetaxel between 2004 and 2012. Samples were histologically categorized as positive/negative.

Median follow-up time from diagnosis was 11.6 years. Nuclear Eg5-expression was significantly related to docetaxel response $(p=0.036)$ in tissues acquired within three years before docetaxel initiation. Nuclear Eg5-expression was not related to Gleason-score $(p=0.994)$. Survival of patients after docetaxel initiation did not differ based on nuclear Eg5-expression $(p=0.540)$. Analyzing samples taken before hormonal therapy, overall survival and time to docetaxel use were significantly decreased in patients with nuclear Eg5-expressing tumors $(p<0.01)$. Eg5-positive nuclei were found more frequently in T4-staged tumors $(p=0.04)$, Gleason 8-10 tumors $(p=0.08)$, and in metastasized tumors $(p<0.01)$. Multivariate analyses indicated that nuclear Eg5expression may be an independent parameter for tumor aggressiveness. Limitations of a retrospective analysis apply.

In conclusion, nuclear Eg5-expression may be a predictive biomarker for docetaxel response in metastatic castrate-resistant PCa patients and a prognostic biomarker for hormone-naive PCa patients. Prospective validation studies are needed.

\section{INTRODUCTION}

Metastatic castrate-resistant prostate cancer (mCRPC) is the second deadliest cancer in men in the Western world [1]. Primary first-line therapy for most mCRPC patients consists of the taxane docetaxel with prednisone [2;3], although various other $\mathrm{mCRPC}$ therapies have recently been introduced [4-8]. About $48 \%$ of patients initially respond to docetaxel therapy [2]; eventually all patients progress during or after docetaxel, usually within few months after their last cycle. As docetaxel inhibits depolarization of microtubules regardless of cell type [9], toxicities may be severe, such as polyneuropathy and bone marrow suppression [2]. To prevent or restrict unnecessary docetaxel use, and to determine the optimal treatment sequence for individual $\mathrm{mCRPC}$ patients [10], biomarkers predicting docetaxel response need to be identified and implemented in clinical practice [11]. 
Table 1: Characteristics of mCRPC patients, their disease and treatment $(n=110)$, and of the obtained tissue $(n=117)$

\begin{tabular}{|c|c|c|c|}
\hline \multicolumn{2}{|l|}{ Patient Age } & & \\
\hline & At time of prostate cancer diagnosis [median (range)] & 64 & $(43-84)$ \\
\hline & At time of obtaining tissue [median (range)] & 65 & $(43-86)$ \\
\hline & At time of start docetaxel [median (range)] & 69 & $(46-87)$ \\
\hline \multicolumn{4}{|c|}{ Disease characteristics (diagnostic imaging) } \\
\hline & Gleason score [median (range)] & & \\
\hline & All patients & 8 & $(4-10)$ \\
\hline & Hormone-naive patients & 8 & $(4-10)$ \\
\hline & Number of metastatic lesions [number of patients $(\%)$ ] & & \\
\hline & 1 & 37 & $(33.6 \%)$ \\
\hline & 2 & 49 & $(44.5 \%)$ \\
\hline & $\geq 3$ & 24 & $(21.8 \%)$ \\
\hline & Localization of metastases [number of patients $(\%)$ ] & & \\
\hline & Lymph node & 71 & $(64.5 \%)$ \\
\hline & Bone & 106 & $(96.4 \%)$ \\
\hline & Liver & 10 & $(9.1 \%)$ \\
\hline & Lung/pleura & 16 & $(14.5 \%)$ \\
\hline & brain & 1 & $(0.9 \%)$ \\
\hline \multicolumn{4}{|c|}{ Treatment characteristics } \\
\hline & Pretreatment [number of patients $(\%)$ ] & & \\
\hline & Androgen-deprivation therapy & 109 & $(99.1 \%)$ \\
\hline & Radical prostatectomy & 15 & $(13.6 \%)$ \\
\hline & TUR-P & 25 & $(22.7 \%)$ \\
\hline & Surgical castration & 4 & $(3.6 \%)$ \\
\hline & Lymph node dissection & 34 & $(30.9 \%)$ \\
\hline & Radiotherapy prostate & 34 & $(30.9 \%)$ \\
\hline & Radiotherapy metastases & 40 & $(36.4 \%)$ \\
\hline & Other & 4 & $(3.6 \%)$ \\
\hline & Docetaxel treatment & & \\
\hline & \# courses [median (range)] & 1 & $(1-3)$ \\
\hline & \# cycles [median (range)] & 6 & $(1-20)$ \\
\hline & Best response [number of patients $(\%)]$ : & & \\
\hline & progressive disease & 22 & $(20.0 \%)$ \\
\hline & stable disease & 38 & $(34.5 \%)$ \\
\hline & partial response & 49 & $(44.5 \%)$ \\
\hline & \begin{tabular}{|l|l} 
& Docetaxel rechallenge [number of patients $(\%)]$ \\
\end{tabular} & 7 & $(6.4 \%)$ \\
\hline & Posttreatment [number of patients $(\%)]$ & 91 & $(82.7 \%)$ \\
\hline & Cabazitaxel & 16 & $(14.5 \%)$ \\
\hline & Abiraterone & 30 & $(27.3 \%)$ \\
\hline & Enzalutamide & 6 & $(5.5 \%)$ \\
\hline & Radiotherapy & 47 & $(42.7 \%)$ \\
\hline
\end{tabular}




\begin{tabular}{|l|l|l|l|l|}
\hline & Strontium-89 & 24 & $(21.8 \%)$ \\
\hline & Samarium-153 & 4 & $(3.6 \%)$ \\
\hline & Mitoxantrone & 15 & $(13.6 \%)$ \\
\hline & Other & 8 & $(7.3 \%)$ \\
\hline & & & \\
\hline Obtained pathological material & & \\
\hline & Type of material [number of samples (\%)] & & \\
\hline & Biopsy & 82 & $(70.0 \%)$ \\
\hline & TUR-P & 24 & $(20.5 \%)$ \\
\hline & Radical prostatectomy & 11 & $(9.4 \%)$ \\
\hline & Disease stage [number of samples (\%)] & & \\
\hline & hormone-naive & 87 & $(74.4 \%)$ \\
\hline & pre-docetaxel & 112 & $(95.7 \%)$ \\
\hline & within three years of start docetaxel & 61 & $(52.1 \%)$ \\
\hline & mCRPC post-docetaxel & 5 & $(4.3 \%)$ \\
\hline Survival & & & \\
\hline & & & & \\
\hline & OS in years [median (IQR)] & 4.8 & $(2.6-9.3)$ \\
\hline & Lost-to-follow-up [number of patients (\%)] & 18 & $(16.4 \%)$ \\
\hline
\end{tabular}

IQR, interquartile range; OS, overall survival; TUR-P, transurethral resection of the prostate

We hypothesized that nuclear Eg5 (Kindle Spindle Protein/KSP/KIF11/kinesin-5) may be such a marker. Eg5 separates spindle poles of a mitotic cell by crosslinking two antiparallel microtubules and moving to the plus-ends of both microtubules [12]. Due to its essential function in mitosis, multiple Eg5-inhibitors have been developed for anti-cancer therapy, such as ispinesib [13]. Two studies with ispinesib focused particularly on mCRPC patients, with ambiguous results. In a phase I study, six out of fourteen mCRPC patients had stable disease (SD) for $\geq 18$ weeks and one patient had a prostate-specific antigen (PSA)-decrease of $>50 \%$ when ispinesib was combined with docetaxel in mCRPC patients [14]. In a phase II study in which ispinesib was administered as monotherapy, no responses were reported [15]. Twenty out of 21 patients had been treated with docetaxel prior to ispinesib. Immunohistochemistry analysis on archival tumor tissue from sixteen patients indicated that only one tumor stained positive for Eg5. It was concluded that ispinesib is not effective in primary prostate cancer $(\mathrm{PCa})$ due to their low mitotic index, resulting in low Eg5 expression. However, considering their similar mechanism of action, an alternative explanation could be that cross-resistance occurs between docetaxel and Eg5-inhibitors.

Recent studies indicate that Eg5 may also play a role in intracellular transport in the cytoplasm, suggesting that Eg5-inhibitors may target Eg5 expressing non-mitotic cells too $[16 ; 17]$. Xing et al. analyzed archival specimens from 80 patients with clinically localized $\mathrm{PCa}$; half stained positive for Eg5, while benign prostate cells did not express Eg5 [18]. Considering the low mitotic index of PCa cells regardless of disease stage [19], these data suggest that Eg5 may indeed be expressed in non-mitotic $\mathrm{PCa}$ cells too [20].

Combining aforementioned findings $[14 ; 15 ; 18]$, initial Eg5 expression of PCa may have been decreased once tumors have become docetaxel resistant. This led to our hypothesis that Eg5 may be a predictive marker for docetaxel response. Based on recent findings that patients with high Gleason-scores respond better to taxane-based therapy [21], we further hypothesize that Eg5 may be a prognostic marker for tumor aggressiveness and clinical outcome.

\section{RESULTS}

\section{Patient and tissue characteristics}

In total, 117 samples were collected from 110 mCRPC patients. These patients had been diagnosed with PCa between 1994 and 2011 and treated with docetaxel between July 15th, 2004 and December 24th, 2012. Median time to follow-up from date of PCa diagnosis was 11.6 years (interquartile range 8.7-14.2 years). Clinicopathological parameters are listed in Table 1. Median age of patients when diagnosed with $\mathrm{PCa}$ was 64 years. Median Gleason-score of tumors was 8 . 
About two-thirds of patients had $\geq 2$ measured metastatic localizations when docetaxel was initiated. Of note, tumor imaging methods such as CT-scans were not performed in all patients, underestimating the number of metastatic lesions. All patients had been medically and/or surgically castrated. In general, patients had been heavily pretreated: patients had received up to five therapies before docetaxel therapy.

For immunohistochemistry, tonsil and healthy prostate tissue served as positive and negative controls, respectively (Fig. 1A-B). Obtained PCa tissue consisted primarily of biopsies (70.0\%) (Table 1, supplementary Fig. 1). In the tumor samples, a clear distinction was observed between samples with nuclear Eg5 staining (5.1\%), cytoplasmic Eg5 staining (19.7\%), and samples staining positive for $\mathrm{Eg} 5$ in both compartments (63.2\%), irrespective of the samples' age (Fig. 1C-F). Samples were scored for nuclear or cytoplasm staining separately.
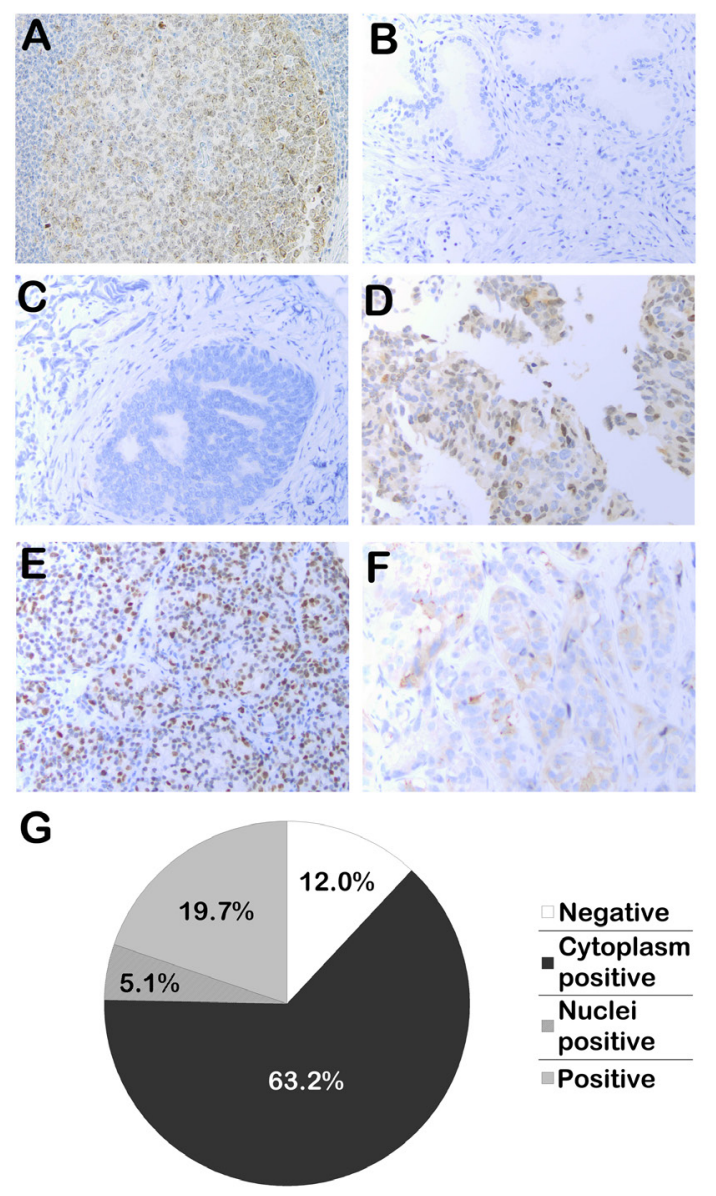

Figure 1: Immunohistochemical analysis of Eg5 expression in human clinical samples. A. Positive control: a lymphatic tissue in a tonsil. B. Negative control: healthy prostate tissue. C. Prostate cancer (PCa) sample staining negative for Eg5. D. PCa sample with Eg5 expression in both the nuclei and cytoplasm. E. PCa sample with nuclear Eg5 expression. F. PCa sample with cytoplasmic Eg5 expression. G. Percentages indicate the frequencies samples with this subcellular staining pattern were found in our sample set $(n=117)$.
Interobserver agreement of scoring was $98.1 \%$.

\section{Immunohistochemical Eg5 expression and docetaxel response}

Eg5 expression varied in tumors from some patients who had multiple biopsies taken before docetaxel therapy. This variability always reflected a disappearance of Eg5 expression over time. It is unknown whether these changes occurred as the tumor evolved spontaneously or due to other therapies, such as androgen-deprivation therapy. Therefore, correlation between Eg5 expression and docetaxel response was evaluated for all patients $(n=110)$ as well as for patients with samples taken within three years before docetaxel start $(n=61)$. A clear trend was observed between nuclear Eg5 expression and a better response to docetaxel therapy (Fig. 2A,

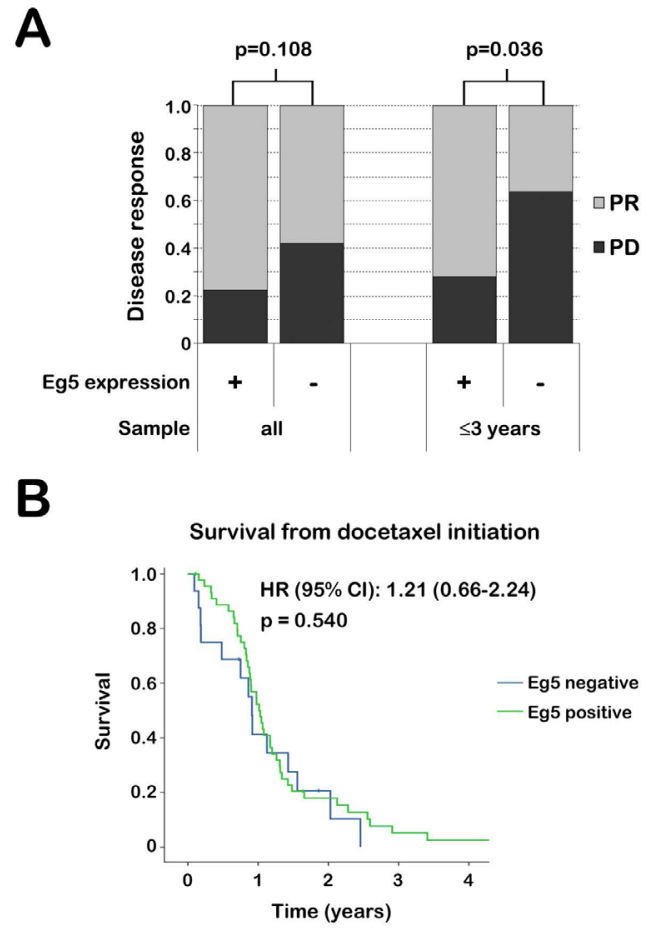

Figure 2: Nuclear Eg5 expression and docetaxel response in $\mathrm{mCRPC}$ patients. A. Best disease response to docetaxel therapy in mCRPC patients, grouped by nuclear Eg5 expression of their tumor. Patients with stable disease (SD) were excluded from this analysis. The most recent $\mathrm{PCa}$ tissue before docetaxel therapy was analyzed from all patients (left) or only from patients who had tissue available obtained from the patient within three years before docetaxel therapy (right). In general, patients with nuclear Eg5 expression had a higher percentage of partial responses (PR). PD, progressive disease. B. Overall survival (OS) after docetaxel initiation. Patients were excluded when they only had PCa tissue available acquired more than three years before docetaxel therapy. Selected mCRPC patients were grouped based on nuclear Eg5 expression of their tumor. Median OS did not differ between patient groups, although initially there is more patient death in the group with Eg5-negative tumors. 
Supplementary Fig. 2). This correlation was significant in patients from whom tissue was taken within three years before docetaxel initiation: $71.9 \%$ of these patients with nuclear Eg5 expression had a PR versus $36.4 \%$ of patients without nuclear Eg5 expression $(\mathrm{p}=0.036)$. Conversely, cytoplasmic or any Eg5 expression did not predict docetaxel response (Supplementary Fig. 3).

As a previous report identified Gleason-scores as a predictive marker for docetaxel response, it was tested whether a correlation existed between Gleason-score and docetaxel response in our set of patient samples (Supplementary Table 1). Gleason-score was not related to docetaxel response, neither in all patients $(\mathrm{p}=0.343)$ nor in patients with tissue available in the three years before docetaxel initiation $(p=0.884)$. Furthermore, Gleasonscore and nuclear Eg5 expression were not related in this latter subpopulation $(\mathrm{p}=0.994)$, suggesting that nuclear Eg5 expression was an independent marker of docetaxel response.

We further explored the correlation between docetaxel response and Eg5 expression by investigating patients who had a PCa sample taken before and after docetaxel treatment. Only five patients matched these criteria. While cytoplasmic Eg5 expression did not alter in these patients, three out of four tumors with positive Eg5 nuclei before docetaxel therapy did not have nuclear Eg5 expression after docetaxel treatment (Supplementary Figure 4). These three patients had progressive disease upon discontinuation of docetaxel. On the other hand, the patient whose tumor expressed nuclear Eg5 pre- and post-docetaxel discontinued docetaxel therapy due to unacceptable toxicities. Despite the small patient number, these results suggested that loss of nuclear Eg5 expression may be related to docetaxel resistance.

Intriguingly, although patients with nuclear Eg5 expression had a better response to docetaxel (Fig. 2A), no difference in OS, calculated from the start of docetaxel therapy to death, was evident between tumors based on nuclear Eg5 expression ( $\mathrm{p}=0.540$ ) (Fig. 2B).
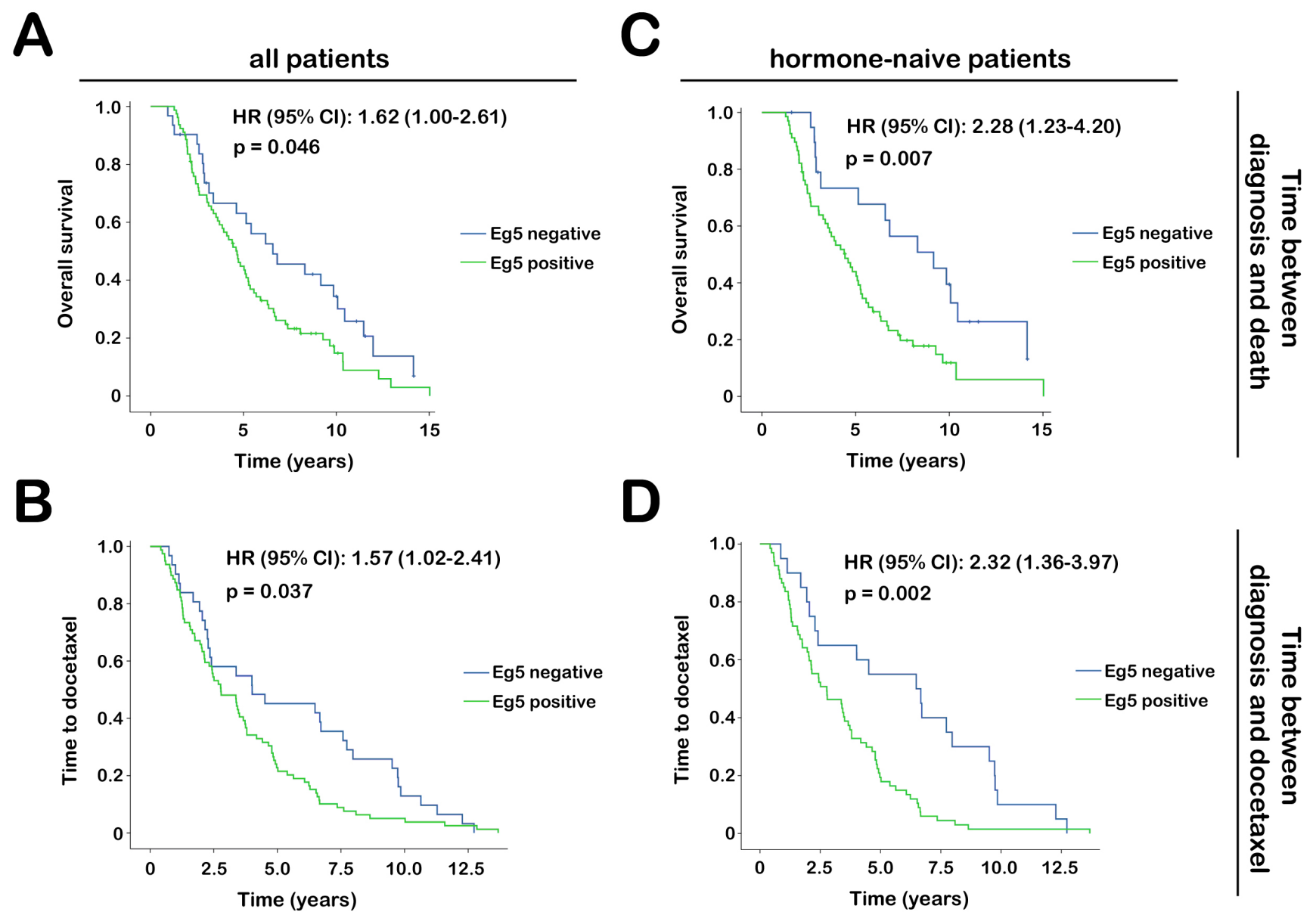

D

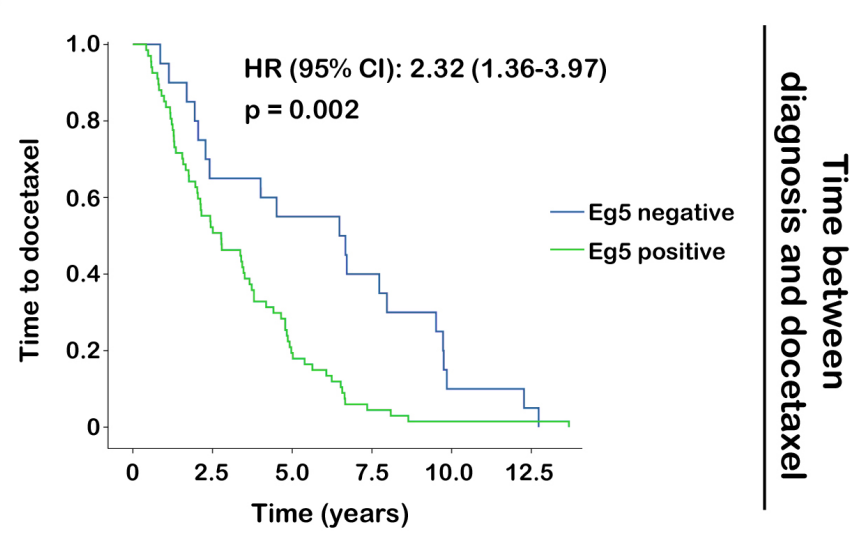

Figure 3: Tumor aggressiveness in mCRPC patients based on Eg5 expression. Patients were selected of whom PCa tissue acquired within three years (left) or three months (right) of diagnosis was available. Patients were divided in groups based on nuclear Eg5 expression. Median OS (top) and time to symptomatic mCRPC (bottom) were compared between patients groups. Patients with tumors that expressed Eg5 upon diagnosis, had a worse clinical outcome. 
Table 2: Multivariate analysis using the Cox-regression model exploring potential confounders for the correlation between nuclear Eg5 expression and tumor aggressiveness

\begin{tabular}{|c|c|c|c|c|c|c|c|c|}
\hline \multirow{3}{*}{$\begin{array}{l}\text { Covariate } \\
\text { Age }\end{array}$} & \multicolumn{4}{|c|}{ All patients } & \multicolumn{4}{|c|}{ Hormone naive patients } \\
\hline & \multicolumn{2}{|c|}{$\begin{array}{l}\text { OS [HR } \\
(95 \% \mathrm{CI})] \\
\end{array}$} & \multicolumn{2}{|c|}{$\begin{array}{l}\text { TTD [HR } \\
(95 \% \mathrm{CI})]\end{array}$} & \multicolumn{2}{|c|}{$\begin{array}{l}\text { OS [HR } \\
(95 \% \mathrm{CI})]\end{array}$} & \multicolumn{2}{|c|}{$\begin{array}{l}\text { TTD [HR } \\
(95 \% \mathrm{CI})]\end{array}$} \\
\hline & 1.56 & $(0.95-2.54)$ & 1.56 & $(1.00-2.42)$ & 2.13 & $(1.13-4.02)$ & 2.29 & $\begin{array}{l}(1.31- \\
3.98)\end{array}$ \\
\hline Gleason & 1.48 & $(0.91-2.40)$ & 1.45 & $(0.94-2.23)$ & 1.76 & $(0.92-3.36)$ & 1.78 & $\begin{array}{l}(1.00- \\
3.18)\end{array}$ \\
\hline Gleason $<7$ and $\geq 7$ & 1.58 & $(0.95-2.63)$ & 1.50 & $(0.95-2.38)$ & 2.61 & $(1.35-5.07)$ & 2.67 & $\begin{array}{l}(1.50- \\
4.75)\end{array}$ \\
\hline Gleason $<8$ and $\geq 8$ & 1.48 & $(0.91-2.40)$ & 1.46 & $(0.95-2.26)$ & 1.84 & $(0.79-3.49)$ & 1.93 & $\begin{array}{l}(1.09- \\
3.41) \\
\end{array}$ \\
\hline T stage & 1.75 & $(1.03-2.99)$ & 1.59 & $(0.99-2.53)$ & 2.56 & $(1.32-4.97)$ & 2.64 & $\begin{array}{l}(1.47- \\
4.75)\end{array}$ \\
\hline Any metastases & 1.52 & $(0.81-2.85)$ & 1.28 & $(0.74-2.22)$ & 2.25 & $(0.99-5.13)$ & 1.97 & $\begin{array}{l}(0.96- \\
4.02)\end{array}$ \\
\hline Distant metastases & 1.40 & $(0.79-2.49)$ & 1.25 & $(0.75-2.08)$ & 1.84 & $(0.87-3.87)$ & 2.33 & $\begin{array}{l}(1.14- \\
4.79) \\
\end{array}$ \\
\hline Number of metastases & 1.64 & $(1.01-2.65)$ & 1.59 & $(1.04-2.44)$ & 2.61 & $(1.35-5.07)$ & 2.67 & $\begin{array}{l}(1.50- \\
4.75)\end{array}$ \\
\hline
\end{tabular}

$\mathrm{CI}$, confidence interval; HR, hazard ratio; OS, overall survival; T stage, T stage according to TNM classification; TTD, time to docetaxel therapy.

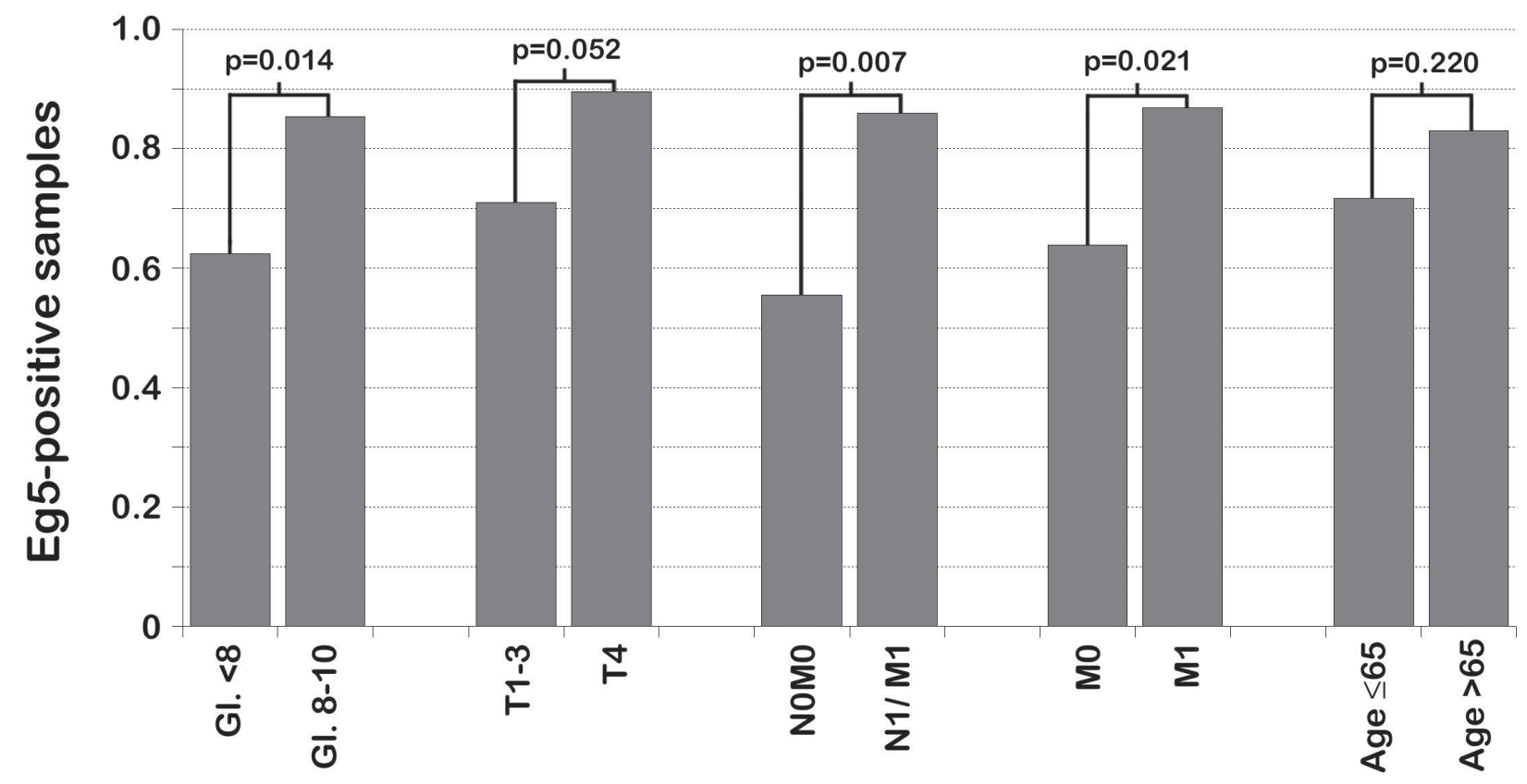

Tumor characteristic

Figure 4: Correlation between PCa characteristics and nuclear Eg5 expression in PCa patients. Patients were selected who had PCa tissue available within three years of PCa diagnosis. Tumors were divided in groups based on Gleason-score and TNM-classification upon diagnosis; the percentage of tumors with Eg5 expressing nuclei was compared. In general, PCa with nuclear Eg5 expression was more aggressive. Gl, Gleason; T, tumor stage according to TNM-classification; $\mathrm{N}$, lymph node metastases ( 0 , no metastases; 1 , metastases); $\mathrm{M}$, distant metastases ( 0 , no metastases; 1 , metastases), N1/M1, any metastases (lymph node and/or distant metastases). 


\section{Immunohistochemical nuclear Eg5 expression and tumor aggressiveness}

We evaluated whether tumors with nuclear Eg5 expression behaved more aggressively. Analyzing samples from all 110 patients, patients with tumors with nuclear Eg5 expression had a significantly decreased OS (median 6.6 versus 4.7 years, $\mathrm{p}=0.046$ ) (Fig. $3 \mathrm{~A}$ ). Time from diagnosis to symptomatic mCRPC was also decreased (median 4.0 versus 2.8 years, $p=0.037$ ) (Fig. 3B). When selecting samples from hormone-naive patients $(\mathrm{n}=87)$, differences in OS and time to symptomatic mCRPC were even more pronounced $(\mathrm{p}=0.010$ and $\mathrm{p}=0.006$, respectively) (Fig. 3C-D). In this subset of patients, nuclear Eg5 expression was related to Gleason-score $(\mathrm{p}=0.014)$ and TNM classification (tumor stage, $\mathrm{p}=0.052$; any metastases, $\mathrm{p}=0.007$; distant metastases, $\mathrm{p}=0.021$ ); no correlation existed between nuclear Eg5 expression and age (Fig. 4).

Multivariate analyses were performed to test whether the correlation between nuclear Eg5 expression and tumor aggressiveness (OS and time to symptomatic mCRPC) remained evident when correcting for potential confounding variables, such as Gleason-score (Table 2). When including all patients, addition of most covariates resulted in no statistically significant correlation between nuclear Eg5 expression and OS or time to symptomatic mCRPC. This included correction for age, while this variable was neither related to nuclear Eg5 expression nor to prognosis, suggesting the study was underpowered for such analyses. However, a trend towards positive nuclear Eg5 expression and aggressive tumors was evident. When assessing hormone-naive patients, a clearly positive trend existed between nuclear Eg5 expression and tumor aggressiveness regardless of the covariate added (hazard ratio $>1.75$ ), suggesting a potential independent prognostic value for nuclear Eg5 expression. The correlation between nuclear Eg5 expression and time to symptomatic mCRPC was significant in all subgroup analyses, except when metastases (N1 and/or M1) were added as a covariate $(\mathrm{p}=0.063)$.

\section{DISCUSSION}

Research has been ongoing identifying prognostic biomarkers and biomarkers predictive for therapy response in PCa with improved accuracy compared to established biomarkers such as serum PSA levels and Gleason-score, with some success [11]. Urokinase plasminogen activator and its inhibitor PAI-1, and Ki-67 have been identified as potential prognostic biomarkers of PCa [22;23]. Cytoplasmic localization of the androgen-receptor and increased blood serum levels of Macrophage Inhibitory Cytokine 1 (MIC-1) have been identified as a potential marker for PCa docetaxel response [24;25]. PCa tumors expressing class III beta-tubulin were relatively insensitive to PCa therapy: class III beta-tubulin expression resulted in faster recurrence after radical prostatectomies, a decreased docetaxel response and decreased survival [26]. Unfortunately, none of these markers are available yet for use in clinical practice [11]. Additional studies, such as the one we present here, are needed to identify a biomarker that is related to docetaxel response in PCa patients.

In the current study, we found that nuclear Eg5 expression in $\mathrm{PCa}$ was associated with improved antitumor efficacy of docetaxel, independently of patient's Gleasonscore. Furthermore, we identified nuclear Eg5 as a prognostic marker in hormone-naive $\mathrm{PCa}$ patients: patients whose tumor expressed nuclear Eg5 had a decreased median OS and progressed more rapidly to mCRPC. Similar findings were reported in non-small lung cancer patients: patients with Eg5 expressing tumors had a better response to chemotherapy, but a lower OS [27]. Similarly, Eg5 expression was related to worse clinical outcome in renal cell carcinoma patients [28].

Once docetaxel was initiated, survival of mCRPC patients was similar irrespective of nuclear Eg5 expression. This may indicate that nuclear Eg5 expressing tumors initially respond well to docetaxel, resulting in decreased patient mortality. However, once these Eg5 expressing tumors progress, these tumors behave more aggressively, increasing patient death. This trend could indeed be derived from the survival curve (Fig. 2B) and might explain why survival of patients with nuclear Eg5 expression is not increased after docetaxel treatment despite responding better to docetaxel therapy. Alternatively, other factors may have resulted in the similar survival curve, such as unequal patient and treatment characteristics between groups other than Eg5 expression.

Nuclear Eg5 expression could provide a useful tool for clinical practice. Interobserver agreement between researchers was very high $(98.1 \%)$, as no subjective degrees of positive staining (mild/moderate/strong) were used. Positive/negative scoring requires little interpretation from the pathologist. Determination of Eg5 expression at the time of diagnosis would be non-invasive, as tissue material is already acquired. Additional tissue sampling once the MCRPC stage has been reached could aid the physician in deciding when to initiate docetaxel therapy. Patients whose tumor expresses nuclear Eg5 may benefit by early docetaxel treatment; patients with $\mathrm{Eg} 5$-negative tumors may be recommended to initiate other therapies first, as docetaxel response is more limited.

In the current study, a retrospective design was chosen, resulting in several limitations. FFPE PCa samples were collected from pathology archives; these samples were taken for diagnostic purposes (biopsies) and consisted of residual materials from surgical procedures such as TUR-P or radical prostatectomies. Therefore, the sample set we created was heterogeneous in origin. 
However, on the contrary to other tumors such as breast cancer, only limited tissue material is available from $\mathrm{PCa}$ patients during their disease, as many patients have a prostatectomy early in their disease and primarily suffer from bone metastases, which are not easily accessible. Furthermore, additional tissue sampling is often not needed, as it currently would not influence further therapy decisions. Therefore, although our initial patient number was relatively large, only limited tissue material was available from patients shortly before docetaxel initiation. Hence all samples taken within three years of docetaxel initiation were collected for analysis. This led to a heterogeneous cohort of samples (both biopsies and residual surgical material), representing various stages of PCa disease. Furthermore, patients may have received various treatments between tissue sampling and docetaxel initiation. E.g., antiandrogen treatment significantly changed gene expression profiles of prostate cancer [29]. It is unknown whether such treatment specifically affects nuclear Eg5 expression. To overcome these challenges, a prospective study will be needed in which tissue will be collected shortly before docetaxel initiation to confirm the correlation between nuclear Eg5 expression and docetaxel response. However, such a study will need to overcome ethical and practical challenges as well.

In addition, our patient population was underpowered for multivariate analyses in hormone-naive patients. Further prospective studies are warranted to validate whether nuclear Eg5 expression may serve as an independent prognostic biomarker.

Previous studies found that $\mathrm{PCa}$ patients with aggressive tumors respond well to docetaxel, but also respond better to cabazitaxel, suggesting that aggressive tumors respond well to taxanes in general [30;31]. Therefore, additional studies are needed to assess whether Eg5 predicts response to cabazitaxel too. Finally, our study results suggest that loss of Eg5 expression may be related to docetaxel resistance. Although ispinesib had limited antitumor efficacy after docetaxel, our study and previous phase I findings suggest that ispinesib may be effective when administered before or concomitantly with docetaxel, when up to $70 \%$ of tumors express nuclear Eg5 [14]. However, combination therapy with docetaxel would need direct comparison to docetaxel monotherapy. Eg5-inhibitors may provide further clinical benefit when selecting mCRPC patients based on nuclear Eg5 expression (personalized medicine).

In conclusion, nuclear Eg5 expressing $\mathrm{PCa}$ is aggressive, but responds well to docetaxel. Loss of nuclear Eg5 expression may be associated with docetaxel resistance. Determining nuclear Eg5 expression in $\mathrm{PCa}$ samples may aid to improve timing to initiate docetaxel therapy in individual PCa patients. Additional prospective studies are needed to confirm the predictive and prognostic value of nuclear Eg5.

\section{METHODS}

\section{Collection of patient material and data}

Formalin fixed and paraffin embedded (FFPE) human PCa samples (biopsies, transurethral resections of prostate (TUR-P) or radical prostatectomies), stored at room temperature, were collected from pathology archives of Leiden University Medical Center, Reinier de Graaf Gasthuis and Erasmus Medical Center Rotterdam. mCRPC patients who had pathological material available taken before docetaxel therapy were included. The study was carried out in accordance with the Dutch code of conduct for the secondary use of human tissues; informed consent was therefore not required when enough material remained to serve the patient's and family's needs [32]. Additional patient information was collected anonymously in a database. Approval was obtained from the Medical Ethics Board (METC) of Leiden University Medical Center (P12.219).

\section{Immunohistochemistry}

Samples ( $3 \mu \mathrm{m}$ sections) were stained for Eg5 using a polyclonal Anti-Eg5 antibody (1:1500, HPA006916, Sigma-Aldrich) on an automated immunohistochemistry stainer (Ventana Benchmark Ultra) (Fig. 1). This stainer utilized the ultraView Universal DAB Detection Kit (760-500, Ventana) for visualization of antibodies. The kit consisted of various enzyme labeled secondary antibodies that bind to primary antibodies; the complex was visualized with hydrogen peroxidase substrate and a 3.30-diaminobenzidine tetrahydrochloride (DAB) chromogen. For antigen retrieval, ULTRA CC1, an EDTA-Tris pH 8.4 solution, was used (950-224, Ventana). Representative images were taken at 20x10 under an Olympus BX41 microscope (Olympus Optical Co., Ltd.) from each slide using a colorview IIIu camera (Olympus), and analyzed with $\mathrm{Cell}^{\wedge} \mathrm{B}$ imaging software (version 2.4108-181207). If an image was representative for the whole slide, only one picture was taken; otherwise, three representative views were imaged per slide.

\section{Data analysis}

Images were examined and scored blindly and independently by two researchers (MDW, ESdM). A clear contrast between nuclear and cytoplasmic Eg5 staining was evident (Fig. 1). Recent studies have indicated that intracellular functions of Eg5 may differ based on its subcellular localization [17]; not all functions may be related to docetaxel response. Therefore, samples were scored for positive or negative staining of nuclei, 
cytoplasm or any cellular compartment (nucleus and/or cytoplasm).

Samples were considered positive when in one highpower field of view $(20 \times 10)$ at least four cancer cells were positive, regardless of intensity. This cut-off value ensured that random mitotic cells, infrequently found in the negative control too, were excluded. For analysis, average scores from both observers were calculated. If $>50 \%$ of all scores per sample were positive for Eg5, the sample was considered Eg5-positive; otherwise it was considered Eg5-negative.

\section{Clinical endpoints}

Clinical endpoints used in this study include survival from docetaxel initiation, overall survival (OS), time to symptomatic mCRPC and best therapy response.

Time to symptomatic mCRPC was defined as time between PCa diagnosis and docetaxel initiation. OS was calculated as time between diagnosis and patient death. If patients had not died or were lost to follow-up, survival was censored at the day the patient was last known to be alive before July 20th, 2013. Tumor aggressiveness was based on OS, time to symptomatic mCRPC, Gleasonscore, and TNM-classification. Determination of best disease response (progressive disease, partial response) followed PCa working group guidelines as described previously, and could indicate PSA response and/ or response as viewed on imaging such as computer tomography [30;33].

\section{Statistical analyses}

Microsoft Excel 2003 was used for basic statistical analyses; student's t-tests were conducted for comparisons. SPSS (version 20) was used for the Kaplan-Meier analyses of survival and time to symptomatic mCRPC; log-rank tests were used to compare these parameters between groups. Multivariate analyses were performed using the Cox-regression model. P-values $\leq 0.050$ were considered statistically significant.

\section{ACKNOWLEDGMENTS}

The authors wish to thank Natalja ter Haar and Michelle Osse for their help with the immunohistochemistry experiments. The authors further wish to thank Carolien Haazer and Edith van Druten for their help collecting the patient samples from the Reinier de Graaf Gasthuis.

\section{FINANCIAL SUPPORT}

This study was supported by Leiden University and Erasmus Medical Center, Rotterdam. JTB was supported by a grant from the Dutch Organization for Scientific Research (NWO, VENI-Grant 916.131.10).

\section{CONFLICT OF INTEREST}

All authors state that they do not have a conflict of interest to disclose.

\section{REFERENCE LIST}

1 Siegel R, Naishadham D, Jemal A. Cancer statistics, 2013. CA Cancer J Clin 2013 Jan;63(1):11-30.

2 Tannock IF, de Wit R, Berry WR, Horti J, Pluzanska A, Chi KN, Oudard S, Theodore C, James ND, Turesson I, Rosenthal MA, Eisenberger MA. Docetaxel plus prednisone or mitoxantrone plus prednisone for advanced prostate cancer. N Engl J Med 2004 Oct 7;351(15):1502-12.

3 Petrylak DP, Tangen CM, Hussain MH, Lara PN, Jr., Jones JA, Taplin ME, Burch PA, Berry D, Moinpour C, Kohli M, Benson MC, Small EJ, Raghavan D, Crawford ED. Docetaxel and estramustine compared with mitoxantrone and prednisone for advanced refractory prostate cancer. $\mathrm{N}$ Engl J Med 2004 Oct 7;351(15):1513-20.

4 de Bono JS, Oudard S, Ozguroglu M, Hansen S, Machiels JP, Kocak I, Gravis G, Bodrogi I, Mackenzie MJ, Shen L, Roessner M, Gupta S, Sartor AO. Prednisone plus cabazitaxel or mitoxantrone for metastatic castrationresistant prostate cancer progressing after docetaxel treatment: a randomised open-label trial. Lancet 2010 Oct 2;376(9747):1147-54.

5 de Bono JS, Logothetis CJ, Molina A, Fizazi K, North $\mathrm{S}$, Chu L, Chi KN, Jones RJ, Goodman Jr. OB, Saad F, Staffurth JN, Mainwaring P, Harland S, Flaig TW, Hutson TE, Cheng T, et al. Abiraterone and increased survival in metastatic prostate cancer. N Engl J Med 2011 May 26;364(21):1995-2005.

6 Ryan CJ, Smith MR, de Bono JS, Molina A, Logothetis CJ, de Souza P, Fizazi K, Mainwaring P, Piulats JM, Ng S, Carles J, Mulders PF, Basch E, Small EJ, Saad F, Schrijvers D, et al. Abiraterone in metastatic prostate cancer without previous chemotherapy. N Engl J Med 2013 Jan 10;368(2):138-48.

7 Scher HI, Fizazi K, Saad F, Taplin ME, Sternberg CN, Miller K, de Wit R, Mulders P, Chi KN, Shore ND, Armstrong AJ, Flaig TW, Flechon A, Mainwaring P, Fleming M, Hainsworth JD, et al. Increased survival with enzalutamide in prostate cancer after chemotherapy. N Engl J Med 2012 Sep 27;367(13):1187-97.

8 Parker C, Nilsson S, Heinrich D, Helle SI, O’Sullivan JM, Fossa SD, Chodacki A, Wiechno P, Logue J, Seke M, 
Widmark A, Johannessen DC, Hoskin P, Bottomley D, James ND, Solberg A, et al. Alpha emitter radium-223 and survival in metastatic prostate cancer. N Engl J Med 2013 Jul 18;369(3):213-23.

9 Jordan MA, Wilson L. Microtubules as a target for anticancer drugs. Nat Rev Cancer 2004 Apr;4(4):253-65.

10 van Soest RJ, van Royen ME, de Morree ES, Moll JM, Teubel W, Wiemer EA, Mathijssen RH, de Wit R, van Weerden WM. Cross-resistance between taxanes and new hormonal agents abiraterone and enzalutamide may affect drug sequence choices in metastatic castration-resistant prostate cancer. Eur J Cancer 2013 Dec;49(18):3821-30.

11 Armstrong AJ, Eisenberger MA, Halabi S, Oudard S, Nanus DM, Petrylak DP, Sartor AO, Scher HI. Biomarkers in the management and treatment of men with metastatic castration-resistant prostate cancer. Eur Urol 2012 Mar;61(3):549-59.

12 Kapitein LC, Peterman EJ, Kwok BH, Kim JH, Kapoor TM, Schmidt CF. The bipolar mitotic kinesin Eg5 moves on both microtubules that it crosslinks. Nature 2005 May 5;435(7038):114-8.

13 Lad L, Luo L, Carson JD, Wood KW, Hartman JJ, Copeland RA, Sakowicz R. Mechanism of inhibition of human KSP by ispinesib. Biochemistry 2008 Mar 18;47(11):3576-85.

14 Blagden SP, Molife LR, Seebaran A, Payne M, Reid AH, Protheroe AS, Vasist LS, Williams DD, Bowen C, Kathman SJ, Hodge JP, Dar MM, de Bono JS, Middleton MR. A phase I trial of ispinesib, a kinesin spindle protein inhibitor, with docetaxel in patients with advanced solid tumours. $\mathrm{Br}$ J Cancer 2008 Mar 11;98(5):894-9.

15 Beer TM, Goldman B, Synold TW, Ryan CW, Vasist LS, Van Veldhuizen PJJ, Dakhil SR, Lara Jr. PN, Drelichman A, Hussain MH, Crawford ED. Southwest Oncology Group phase II study of ispinesib in androgen-independent prostate cancer previously treated with taxanes. Clin Genitourin Cancer 2008 Sep;6(2):103-9.

16 Wissing MD, van Diest PJ, van der Wall E, Gelderblom H. Antimitotic agents for the treatment of patients with metastatic castrate-resistant prostate cancer. Expert Opin Investig Drugs 2013 May;22(5):635-61.

17 Wakana Y, Villeneuve J, van GJ, Cruz-Garcia D, Tagaya M, Malhotra V. Kinesin-5/Eg5 is important for transport of CARTS from the trans-Golgi network to the cell surface. J Cell Biol 2013 Jul 22;202(2):241-50.

18 Xing ND, Ding ST, Saito R, Nishizawa K, Kobayashi T, Inoue T, Oishi S, Fujii N, Lv JJ, Ogawa O, Nishiyama H. A potent chemotherapeutic strategy in prostate cancer: S-(methoxytrityl)-L-cysteine, a novel Eg5 inhibitor. Asian J Androl 2011 Mar;13(2):236-41.

19 Berges RR, Vukanovic J, Epstein JI, CarMichel M, Cisek L, Johnson DE, Veltri RW, Walsh PC, Isaacs JT. Implication of cell kinetic changes during the progression of human prostatic cancer. Clin Cancer Res 1995 May;1(5):473-80.

20 Wissing MD, Carducci MA, Gelderblom H, van Diest PJ.
Tales of how great drugs were brought down by a flawed rationale--letter. Clin Cancer Res 2013 Mar 1;19(5):1303.

21 van Soest RJ, de Morree ES, Shen L, Tannock IF, Eisenberger MA, de Wit R. Initial Biopsy Gleason Score as a Predictive Marker for Survival Benefit in Patients with Castration-resistant Prostate Cancer Treated with Docetaxel: Data from the TAX327 Study. Eur Urol 2013 Aug 11.

22 Gupta A, Lotan Y, Ashfaq R, Roehrborn CG, Raj GV, Aragaki CC, Montorsi F, Shariat SF. Predictive value of the differential expression of the urokinase plasminogen activation axis in radical prostatectomy patients. Eur Urol 2009 May;55(5):1124-33.

23 Rubio J, Ramos D, Lopez-Guerrero JA, Iborra I, Collado A, Solsona E, Almenar S, Llombart-Bosch A. Immunohistochemical expression of Ki-67 antigen, cox2 and $\mathrm{Bax} / \mathrm{Bcl}-2$ in prostate cancer; prognostic value in biopsies and radical prostatectomy specimens. Eur Urol 2005 Nov;48(5):745-51.

24 Darshan MS, Loftus MS, Thadani-Mulero M, Levy BP, Escuin D, Zhou XK, Gjyrezi A, Chanel-Vos C, Shen R, Tagawa ST, Bander NH, Nanus DM, Giannakakou P. Taxane-induced blockade to nuclear accumulation of the androgen receptor predicts clinical responses in metastatic prostate cancer. Cancer Res 2011 Sep 15;71(18):6019-29.

25 Zhao L, Lee BY, Brown DA, Molloy MP, Marx GM, Pavlakis N, Boyer MJ, Stockler MR, Kaplan W, Breit SN, Sutherland RL, Henshall SM, Horvath LG. Identification of candidate biomarkers of therapeutic response to docetaxel by proteomic profiling. Cancer Res 2009 Oct 1;69(19):7696-703.

26 Ploussard G, Terry S, Maille P, Allory Y, Sirab N, Kheuang L, Ploussard G, Terry S, Maille P, Allory Y, Sirab N, Kheuang L, Soyeux P, Nicolaiew N, Coppolani E, Paule B, et al. Class III beta-tubulin expression predicts prostate tumor aggressiveness and patient response to docetaxel-based chemotherapy. Cancer Res 2010 Nov 15;70(22):9253-64.

27 Saijo T, Ishii G, Ochiai A, Yoh K, Goto K, Nagai K, Kato H, Nishiwaki Y, Saijo N. Eg5 expression is closely correlated with the response of advanced non-small cell lung cancer to antimitotic agents combined with platinum chemotherapy. Lung Cancer 2006 Nov;54(2):217-25.

28 Sun D, Lu J, Ding K, Bi D, Niu Z, Cao Q, Zhang J, Ding S. The expression of Eg5 predicts a poor outcome for patients with renal cell carcinoma. Med Oncol 2013 Mar;30(1):476.

29 Holzbeierlein J, Lal P, LaTulippe E, Smith A, Satagopan J, Zhang L, Ryan C, Smith S, Scher H, Scardino P, Reuter $\mathrm{V}$, Gerald WL. Gene expression analysis of human prostate carcinoma during hormonal therapy identifies androgenresponsive genes and mechanisms of therapy resistance. Am J Pathol 2004 Jan;164(1):217-27.

30 Wissing MD, van Oort IM, Gerritsen WR, van den Eertwegh AJ, Coenen JL, Bergman AM, Gelderblom H. Cabazitaxel in patients with metastatic castration- 
resistant prostate cancer: results of a compassionate use program in the Netherlands. Clin Genitourin Cancer 2013 Sep;11(3):238-50.

31 Oudard S, De Bono JS, Özgüroglu M, Hansen S, Machiels JP, Kocak I, Gravis G, Bodrogi I, Shen L, Sartor AO. Impact of cabazitaxel $(\mathrm{Cbz})+$ prednisone $(\mathrm{P} ; \mathrm{CbzP})$ on overall survival (OS) at 2 yrs and in patients (pts) with aggressive disease: post-hoc analyses of TROPIC trial. [abstract]. Ann Oncol 2012;23 (Suppl 9; abstr 1857).

32 van Diest PJ. No consent should be needed for using leftover body material for scientific purposes. For. BMJ 2002 Sep 21;325(7365):648-51.

33 Scher HI, Halabi S, Tannock I, Morris M, Sternberg CN, Carducci MA, Eisenberger MA, Higano C, Bubley GJ, Dreicer R, Petrylak D, Kantoff P, Basch E, Kelly WK, Figg WD, Small EJ, et al. Design and end points of clinical trials for patients with progressive prostate cancer and castrate levels of testosterone: recommendations of the Prostate Cancer Clinical Trials Working Group. J Clin Oncol 2008 Mar 1;26(7):1148-59. 